\title{
Postoperative Shock as Independent Factor for Incisional Surgical Site Infection in Left-Side Colorectal Perforation
}

\author{
Hiroshi Asano $^{1}$ (D) Hiroyuki Fukano $^{1} \cdot$ Nozomi Shinozuka $^{1}$
}

Accepted: 18 February 2020 / Published online: 28 February 2020

(C) The Author(s) 2020

\begin{abstract}
The incidence of incisional surgical site infection (SSI) in patients with colorectal perforation is reported to be approximately $40 \%$. Although these subcutaneous drains and wound protector are performed using a wound closure method aimed to prevent incisional SSI, the evidence for colorectal perforation is poor. Although delayed primary closure (DPC) is reported to be an effective method to maintain open wounds, its management is time-consuming and cannot be performed in all cases. Therefore, the closure method should be carefully selected based on the risk of SSI. This study aimed to evaluate the risk factors of incisional SSI in left-side colorectal perforation with stoma creation. A total of 130 patients who underwent emergency surgery for left-side colorectal perforation with stoma creation between 2007 and 2017 were retrospectively investigated. Univariable and multivariable analyses were used to identify risk factors for incisional SSI. The total number of patients with incisional SSI was 58 (45\%). In the univariate analysis, postoperative shock, postoperative ventilator support, and base excess $(<-2.0)$ were correlated with higher risk of incisional SSI. Multivariate analysis showed that postoperative shock was an independent risk factor for incisional SSI (odds ratio, 2.60; 95\% confidence interval, 1.06-6.37). Postoperative shock is the risk factor of incisional SSI in left-side colorectal perforation with stoma. DPC should be considered in case of colorectal perforation combined with shock.
\end{abstract}

Keywords Colorectal perforation $\cdot$ Incisional SSI $\cdot$ Delayed primary closure $\cdot$ Shock

\section{Introduction}

In gastroenterological surgery, bacterial contamination in the intraperitoneal and subcutaneous tissues may possibly occur, which are originally aseptic, due to resection anastomosis of the gastrointestinal tract, and the occurrence of surgical site infection (SSI) is common. In the recent years, although the incidence rate has decreased due to perioperative management based on the evidence obtained by the Center for Disease Control (CDC) guidelines and efforts of each facility, the occurrence of SSI in abdominal emergency surgery remains high [1].

SSI is classified into incisional SSI and organ/space SSI. Incisional SSI is a common complication, and countermeasure is an important problem since it will be a burden to both

This article is part of the Topical Collection on Surgery

Hiroshi Asano

hiroshia@saitama-med.ac.jp

1 Department of General Surgery, Saitama Medical University, 38 Morohongou Moroyama Irumagun, Saitama 350-0495, Japan patients and medical personnel, such as increased length of hospital stay, increased medical cost, and development of incisional hernias, if once occurred [2-4].

Measures such as wound protectors, intraperitoneal irrigation, and subcutaneous drain during wound closure have been reported to prevent incisional SSI [5-9]; however, evidences on operations with severe contamination such as colorectal perforation are lacking although less contamination can be expected in elective operations. Delayed primary closure (DPC) is adapted as a wound closure method for patients with severely contaminated peritonitis. This was reported as a wound management method for trauma during the First World War and later became widely used for surgical wounds $[10,11]$. DPC is the standard practice in the USA for contamination surgery and is used even in Japan. However, since the burden on patients and medical staff such as open wound management and re-suturing slightly increased, it is not a desirable closure method for all cases. Various factors such as wound contamination, obesity, and use of steroids are considered to affect the occurrence of incisional SSI $[2,12,13]$. If the risk factors are clarified, appropriate measures can be taken for each case. Therefore, this study retrospectively investigated 
the surgical cases in order to clarify the risk factors of incisional SSI in colorectal perforation.

\section{Methods}

Patients who underwent emergency surgery with stoma creation for left-sided colorectal perforation with generalized peritonitis at our department, between January 2007 and December 2017, were retrospectively examined. This study was approved by the Institutional Review Board of Saitama Medical University Hospital (No. 17013). Patients with iatrogenic or traumatic causes and those who died within 30 days were excluded.

Some patients who underwent DPC during the study period but did not meet the selection criteria of wound closure method were also excluded, and only patients who underwent primary closure were investigated.

The dependent variable in this study was incisional SSI, which included both superficial and deep infections. The SSI diagnosis was based on the definition of the CDC guideline [14]. Incisional SSI was defined as an infection that occurred at the incision site within 30 days postoperatively and was characterized by at least one of the following: (1) purulent discharge, (2) organisms isolated from an aseptically obtained culture of fluid or tissue, (3) at least one of the following signs or symptoms of infection: pain or tenderness, localized swelling, redness, or heat with opening of incision, and (4) diagnosis by the surgeon or attending physician. Superficial SSI involves the skin and subcutaneous tissue only, whereas deep SSI involves the fascial and muscle layers.

Independent variables for analysis were cause of perforation, time after onset, diabetes mellitus, body mass index (BMI), use of steroids, chronic renal failure, white blood cell counts, serum albumin concentration, base excess (BE), preoperative sequential organ failure assessment (SOFA) score, duration of operation, blood loss, severity of peritoneal contamination, intraperitoneal infection, postoperative shock, and postoperative ventilator support. Body mass index was calculated from the patient's height and weight $\left(\mathrm{kg} / \mathrm{m}^{2}\right)$. Intraperitoneal infection was assessed in accordance with the Hinchey classification [15], with Hinchey III defined as generalized peritonitis associated with purulent ascites and Hinchey IV defined as generalized peritonitis associated with fecal matter. Postoperative shock was defined as a condition requiring catecholamine administration to maintain circulation. All continuous variables were converted to categorical variables by setting the following cut-off values: time after onset $(\geq 24 \mathrm{~h},<24 \mathrm{~h})$, body mass index $(\geq 25,<25)$, white blood cells $(<4000 / \mu \mathrm{l}, \geq 4000 / \mu \mathrm{l})$, serum albumin concentration $(<3.0 \mathrm{mg} / \mathrm{dl}, \geq 3.0 \mathrm{mg} / \mathrm{dl}), \mathrm{BE}(<-2.0, \geq-2.0)$, SOFA score $(\geq 2,<2)$, duration of operation $(\geq 2 \mathrm{~h},<2 \mathrm{~h}$ ), and blood loss $(\geq 500 \mathrm{ml},<500 \mathrm{ml})$. The results of blood examination were obtained immediately before the operation.

\section{Surgical Technique}

In all cases, colorectal perforation was performed via laparotomy. In principle, colostomy consisted of the Hartmann's procedure, in which the perforation site is resected and an end colostomy is formed from the proximal end. However, in some cases, the intestine was anastomosed after resecting the perforation site, and the stoma was formed at the proximal diversion. In other cases, the perforation site was directly extracted from the body to make a colostomy (exteriorization). The peritoneum was washed with $\geq 10,000 \mathrm{ml}$ of saline solution, and a closed drain was implanted in the pelvic floor. The muscle layer in the abdomen was closed using interrupted monofilament absorbable sutures, and the skin was closed with subcutaneous monofilament absorbable sutures after washing the subcutaneous tissue with $1000 \mathrm{ml}$ of saline solution. Carbapenem was administered as a perioperative antibacterial drug treatment starting before the operation, with de-escalation as appropriate based on postoperative culture results.

\section{Statistical Analysis}

Statistical analysis was performed using Excel (Microsoft, Seattle, WA) and BellCurve for Excel (Social Survey Research Information Co., Ltd., Tokyo, Japan). The univariate analysis was evaluated using $\chi^{2}$ test. Statistical significance was defined as $p<0.05$. Independent variables with statistical significance were used in the multivariate analysis.

\section{Results}

During the study period, there were 134 cases of left-side colorectal perforation for which primary closure and stoma creation were performed, and 9 of them died in the hospital (mortality rate $7 \%$ ). With deaths within 30 days after surgery excluded, the study considered a total of 130 cases. Patient characteristics are shown in Table 1. The cohort comprised 57 men and 73 women with a mean age of 72.8 years. The most common cause of perforation was diverticulum (47 patients), followed by idiopathic disease (40 patients) and malignancy (38 patients). The most common perforation sites were the sigmoid colon ( 87 patients), rectum ( 30 patients), and descending colon (13 patients). The total number of patients with incisional SSI was 58 patients $(45 \%)$. Colostomy was performed with Hartmann's procedure, proximal diversion, and exteriorization in 110,12 , and 8 patients, respectively. The rates of SSI in patients with and without anastomosis were $58 \%$ and $43 \%$, respectively, and no significant difference 
Table 1 Patient characteristics

\begin{tabular}{ll}
\hline Variable & Frequency \\
\hline No. of patients & 130 \\
Age (years) & 72.8 \\
Sex (M/F) & $57 / 73$ \\
Cause of perforation & \\
$\quad$ Diverticulum & 47 \\
Idiopathic & 40 \\
Malignancy & 38 \\
Ulcer & 3 \\
Ischemia & 1 \\
Others & 1 \\
Site of perforation & \\
Rectum & 30 \\
Sigmoid & 87 \\
Descending & 13 \\
Incisional SSI & $58(45 \%)$ \\
\hline
\end{tabular}

SSI surgical site infection

was identified (Table 2). In the univariate analysis, postoperative shock ( $67 \%$ vs $34 \%, p<0.001)$, postoperative ventilator support ( $60 \%$ vs $33 \%, p=0.002)$, and $\mathrm{BE}(<-2.0)(57 \%$ vs $37 \%, p=0.02)$ correlated with higher risk of incisional SSI (Table 3). Multivariate analysis showed that postoperative shock was an independent risk factor for incisional SSI (odds ratio, 2.60; 95\% confidence interval, 1.06-6.37) (Table 4).

\section{Discussion}

Our study showed that postoperative shock, postoperative ventilator support, and $\mathrm{BE}(<-2.0)$ were correlated with higher risk of incisional SSI. Further, postoperative shock was an independent risk factor for incisional SSI.

Among the gastrointestinal surgeries, the incidence of incisional SSI in colorectal surgery is high, which is reported to be approximately $40 \%$, especially in colorectal perforation $[2,6,16-18]$. The incidence of incisional SSI in this study was $45 \%$ and $67 \%$ if combined with postoperative shock, which is extremely high. Although a significant amount of bacteria remaining in the wound during wound closure is involved in the occurrence of incisional SSI, if a certain amount of bacteria that leads to infection is not established, wound healing occurs, but if the number of bacteria increases, infection is established. Incisional SSI is expected to occur in patients with postoperative shock because the antimicrobial drugs

were not delivered to the wound site, making them ineffective and because contamination is extremely strong in gastrointestinal perforation. Therefore, the amount of bacteria should be considered not sufficiently eliminated despite the irrigation.

In general, some factors such as smoking, obesity, and diabetes mellitus are reported as risk factors for SSI occurrence $[9,19]$ but in elective surgery, countermeasures such as smoking cessation or weight reduction may also be considered; however, it is difficult in emergency surgery. In colorectal surgery, the left-side colon and stoma creation are also mentioned [17, 20]; however, taking measures specifically for each disease is difficult. Therefore, measures should be taken during wound closure rather than risk elimination.

Fujii et al. [21] reported effects of subcutaneous drains for incisional SSI in obese patients. In cases with subcutaneous fat tissue of $>20 \mathrm{~mm}$ in colorectal emergency surgery, SSI has been improved from 39 to $14 \%$ by placing a subcutaneous drain. In addition, Watanabe et al. [9] reported that subcutaneous drainage effectively prevented incisional SSI in their RCT on 200 cases of colorectal surgery. Conversely, Baier et al. [22] reported that subcutaneous drainage has no effect on incisional SSI in their RCT with the same number of cases. Therefore, the usefulness of subcutaneous drainage is controversial, especially that no evidence exists in colorectal perforation.

Antimicrobial suture is a suture coated with triclosan to prevent increased bacterial attachment to the suture, considering that the foreign material in the wound is the cause of incisional SSI. Regarding this effect, Galal et al. [23] reported in their RCT on 450 cases that although patients underwent various types of operations, the control was $15 \%$, whereas the occurrence of SSI due to antimicrobial suture was $7 \%$. Moreover, they reported that antimicrobial suture decreased the incidence of SSI in contaminated operations (control 31\% vs. antimicrobial suture 14\%). On the contrary, the systematic review and meta-analysis of 7 RCTs with 836 cases reported that antimicrobial suture could not reduce the SSI occurrence [24]; however, this requires further data accumulation.

A number of previous studies identified stoma creation as a risk factor of SSI in emergency colorectal surgeries [16, 17, 20]. It is known to be caused by fecal wound contamination due to the proximity from the stoma. Yamamoto et al. [16] implemented a bundle of closing the incision with antimicrobial suture and covered the incision with a cyanoacrylate tissue adhesive in a case of stoma creation caused by colorectal perforation, and the incidence of SSI decreased to 20 from $43 \%$. Because the SSI incidence rate is decreasing due to

Table 2 Operative procedure and incisional SSI

\begin{tabular}{lccc}
\hline & No. & Incisional SSI & $p$ value \\
\hline Without anastomosis (Hartmann's procedure, exteriorization) & 118 & $51(43 \%)$ & 0.32 \\
Anastomosis and diversion stoma & 12 & $7(58 \%)$ & \\
\hline
\end{tabular}


Table 3 Operative procedure and incisional SSI

\begin{tabular}{|c|c|c|c|c|}
\hline Variable & & No. & Incisional SSI $(n=58)$ & $p$ value \\
\hline \multirow[t]{2}{*}{ Cause of perforation } & With malignancy & 38 & $16(42 \%)$ & \multirow[t]{2}{*}{0.71} \\
\hline & Without malignancy & 92 & $42(46 \%)$ & \\
\hline \multirow[t]{2}{*}{ Time after onset } & $\geq 24 \mathrm{~h}$ & 41 & $18(44 \%)$ & \multirow[t]{2}{*}{0.91} \\
\hline & $<24 \mathrm{~h}$ & 89 & $40(45 \%)$ & \\
\hline \multirow[t]{2}{*}{ Diabetes mellitus } & With & 11 & $2(18 \%)$ & \multirow[t]{2}{*}{0.07} \\
\hline & without & 119 & $56(47 \%)$ & \\
\hline \multirow[t]{2}{*}{ Body mass index } & $\geq 25$ & 23 & $10(43 \%)$ & \multirow[t]{2}{*}{0.90} \\
\hline & $<25$ & 107 & $48(45 \%)$ & \\
\hline \multirow[t]{2}{*}{ Steroid use } & With & 10 & $3(30 \%)$ & \multirow[t]{2}{*}{0.33} \\
\hline & Without & 120 & $55(46 \%)$ & \\
\hline \multirow[t]{2}{*}{ Chronic renal failure } & With & 15 & $5(33 \%)$ & \multirow[t]{2}{*}{0.35} \\
\hline & Without & 115 & $53(46 \%)$ & \\
\hline \multirow[t]{2}{*}{ White blood cell } & $<4000 / \mu 1$ & 48 & $23(48 \%)$ & \multirow[t]{2}{*}{0.56} \\
\hline & $\geq 4000 / \mu 1$ & 82 & $35(42 \%)$ & \\
\hline \multirow[t]{2}{*}{ Serum albumin } & $<3.0 \mathrm{mg} / \mathrm{dl}$ & 44 & $21(48 \%)$ & \multirow[t]{2}{*}{0.61} \\
\hline & $\geq 3.0 \mathrm{mg} / \mathrm{dl}$ & 86 & $37(43 \%)$ & \\
\hline \multirow[t]{2}{*}{$\mathrm{BE}$} & $<-2.0$ & 51 & $29(57 \%)$ & \multirow[t]{2}{*}{0.02} \\
\hline & $\geq-2.0$ & 79 & $29(37 \%)$ & \\
\hline \multirow[t]{2}{*}{ SOFA score } & $\geq 2$ & 74 & $36(49 \%)$ & \multirow[t]{2}{*}{0.24} \\
\hline & $<2$ & 55 & $21(38 \%)$ & \\
\hline \multirow[t]{2}{*}{ Duration of operation } & $\geq 2 \mathrm{~h}$ & 64 & $32(50 \%)$ & \multirow[t]{2}{*}{0.22} \\
\hline & $<2 \mathrm{~h}$ & 66 & $26(39 \%)$ & \\
\hline \multirow[t]{2}{*}{ Blood loss } & $\geq 500 \mathrm{ml}$ & 22 & $13(59 \%)$ & \multirow[t]{2}{*}{0.13} \\
\hline & $<500 \mathrm{ml}$ & 108 & $45(42 \%)$ & \\
\hline \multirow[t]{2}{*}{ Severity of peritoneal contamination } & Hinchey IV & 54 & $26(48 \%)$ & \multirow[t]{2}{*}{0.49} \\
\hline & Hinchey III & 76 & $32(42 \%)$ & \\
\hline \multirow[t]{2}{*}{ Postoperative shock } & With & 42 & $28(67 \%)$ & \multirow[t]{2}{*}{$<0.001$} \\
\hline & Without & 88 & $30(34 \%)$ & \\
\hline \multirow[t]{2}{*}{ Ventilator support } & Without & 57 & $34(60 \%)$ & \multirow[t]{2}{*}{0.002} \\
\hline & Without & 73 & $24(33 \%)$ & \\
\hline
\end{tabular}

$B E$ base excess, SOFA sequential organ failure assessment wound covering, wound site contamination is greatly affected. However, although our study examined only cases with stoma, its occurrence rate combined with shock is high not only in the contaminated wound site but also due to the large influence of various factors.

However, even if stomas are a risk factor for SSI, stoma creation cannot be avoided. Although some countermeasures could be implemented if operation time and blood loss volume

Table 4 Multivariate analysis

\begin{tabular}{llll}
\hline & Odds ratio & $95 \%$ CI & $p$ value \\
\hline BE & 1.64 & $0.75-3.55$ & 0.21 \\
Postoperative shock & 2.60 & $1.06-6.37$ & 0.04 \\
Ventilator support & 1.74 & $0.75-4.04$ & 0.20 \\
\hline
\end{tabular}

$B E$ base excess were risk factors, the risks also identified in this study were uncontrollable factors such as BE, postoperative respiratory management, and shock. Generally speaking, factors such as Hinchey classification, blood loss volume, and use of steroids are considered possible risk factors for incisional SSI. However, conditions such as shock, circulation impairment, and hypoxemia also delay incision healing. Since colorectal perforation is accompanied by generalized peritonitis, which can easily cause shock and respiratory difficulties, postoperative shock and artificial respirator management may have a stronger effect on the occurrence of SSI.

Although surgeons are hesitant to perform temporary closure on incision sites with such a high risk of infection, consideration of management for open wounds is also necessary.

DPC is a closure method performed on contaminated wounds, through wound maintenance with closed muscular layer and packed with saline-soaked gauze. In addition, the 
wound will close naturally if no infection occurs within a few days. It is performed not only for contaminated wounds such as trauma but also for surgical wounds [11]. Cohn et al. [25] reported that DPC was performed on gastrointestinal perforation and trauma creation, and the SSI incidence rate improved from 48 to $15 \%$.

Although secondary treatment is conducted with the wound left open if bed preparation has not progressed when SSI occurs after closure, negative pressure therapy (NPT) has also been reported as a potential treatment for open wounds in recent years. NPT draws out fluid from the wound and increases blood flow to the area, which promotes bed preparation. It had been commonly used for the treatment of open wounds since 1997 when it was first reported [26, 27]. Although it is used for SSI with the expectation that it could promote faster closure of the open wound, there have been reports in recent years that it could prevent wound infection as well. In addition to the method of packing the open wound with foam immediately after surgery and using negative pressure for management and reduction [28], other methods such as temporarily closing the wound, applying foam over the top, and using negative pressure for management are also used [29]. However, treatment requirements such as frequent replacement of equipment make NPT less cost-effective than DPC, and due to this medical economics problem, it is not used as a preventive treatment at this hospital.

This study aimed to identify cases that require DPC, and based on its results, DPC should be selected instead of primary closure in cases with shock. However, the incidence of nonshock cases is also $34 \%$ and cannot be ignored; thus, primary closure together with other measures is necessary, which should be investigated in future studies.

The limitation of this study is that some cases underwent DPC during the period. Criteria to select DPC were not determined; however, DPC seems empirically performed in cases highly at risk of SSI.

Although the number of subjects was 130 , the target period should be as long as approximately 10 years. Although there are no major changes in the treatment policy during that period, unknown factors also arose and were considered as a prognostic change accompanying advances in therapeutic drugs and wound management. From now on, new countermeasures such as washing the subcutaneous tissue at wound closure and closing the wound by instrument exchange and establishing SSI measures should be established.

\section{Conclusion}

This study showed that the shock combined case was an independent risk factor for incisional SSI occurrence in left-side colorectal perforation with stoma. As the incisional SSI incidence rate combined with shock is $67 \%$, DPC should be performed rather than primary closure. Because incisional SSI in this study occurs in $45 \%$ of the total study population, some countermeasures should be performed in cases without shock.

Authors' Contributions HA and HF performed the operation and participated in the treatment of these patients. HA and NS revised the manuscript. All authors read and approved the final version of this manuscript.

\section{Compliance with Ethical Standards}

Conflict of Interest The authors declare that they have no conflict of interest.

Ethical Approval All procedures performed in studies involving human participants were in accordance with the ethical standards of the institutional and/or national research committee and with the 1964 Helsinki declaration and its later amendments or comparable ethical standards.

For this type of study, formal consent is not required.

Open Access This article is licensed under a Creative Commons Attribution 4.0 International License, which permits use, sharing, adaptation, distribution and reproduction in any medium or format, as long as you give appropriate credit to the original author(s) and the source, provide a link to the Creative Commons licence, and indicate if changes were made. The images or other third party material in this article are included in the article's Creative Commons licence, unless indicated otherwise in a credit line to the material. If material is not included in the article's Creative Commons licence and your intended use is not permitted by statutory regulation or exceeds the permitted use, you will need to obtain permission directly from the copyright holder. To view a copy of this licence, visit http://creativecommons.org/licenses/by/4.0/.

\section{References}

1. Silvestri M, Dobrinja C, Scomersi S, Giudici F, Turoldo A, Princic E, et al. Modifiable and non-modifiable risk factors for surgical site infection after colorectal surgery: a single-center experience. Surg Today. 2018;48:338-45.

2. Smith RL, Bohl JK, McElearney ST, Friel CM, Barclay MM, Sawyer RG, et al. Wound infection after elective colorectal resection. Ann Surg. 2004;239:599-607.

3. Henriksen NA, Deerenberg EB, Venclauskas L, Fortelny RH, Garcia-Alamino JM, Miserez M, et al. Triclosan-coated sutures and surgical site infection in abdominal surgery: the TRISTAN review, meta-analysis and trial sequential analysis. Hernia. 2017;21:833-41.

4. Murray BW, Cipher DJ, Pham T, Anthony T. The impact of surgical site infection on the development of incisional hernia and small bowel obstruction in colorectal surgery. Am J Surg. 2011;202: 558-60.

5. Itatsu K, Yokoyama Y, Sugawara G, Kamiya S, Terasaki M, Morioka A, et al. The benefits of a wound protector in preventing incisional surgical site infection in elective open digestive surgery: a large-scale cohort study. World J Surg. 2017;41:2715-22.

6. Mihaljevic AL, Schirren R, Özer M, Ottl S, Grün S, Michalski CW, et al. Multicenter double-blinded randomized controlled trial of standard abdominal wound edge protection with surgical dressings versus coverage with a sterile circular polyethylene drape for 
prevention of surgical site infections: a CHIR-Net trial (BaFO; NCT01181206). Ann Surg. 2014;260:730-7.

7. Nikfarjam M, Kimchi ET, Gusani NJ, Avella DM, Shereef S, Staveley-O'Carroll KF, et al. Reduction of surgical site infections by use of pulsatile lavage irrigation after prolonged intra-abdominal surgical procedures. Am J Surg. 2009;198:381-6.

8. Mueller TC, Loos M, Haller B, Mihaljevic AL, Nitsche U, Wilhelm $\mathrm{D}$, et al. Intra-operative wound irrigation to reduce surgical site infections after abdominal surgery: a systematic review and metaanalysis. Langenbeck's Arch Surg. 2015;400:167-81.

9. Watanabe J, Ota M, Kawamoto M, Akikazu Y, Suwa Y, Suwa H, et al. A randomized controlled trial of subcutaneous closed-suction Blake drains for the prevention of incisional surgical site infection after colorectal surgery. Int J Color Dis. 2017;32:391-8.

10. Pool EH. War wounds. J Am Med Assoc. 1919;73:383-8.

11. Tobin GR. An improved method of delayed primary closure. An aggressive management approach to unfavorable wounds. Surg Clin North Am. 1984;64:659-66.

12. Amri R, Bordeianou LG, Sylla P, Berger DL. Obesity, outcomes and quality of care: body mass index increases the risk of woundrelated complications in colon cancer surgery. Am J Surg. 2014;207:17-23.

13. Hedrick TL, Sawyer RG, Friel CM, Stukenborg GJ. A method for estimating the risk of surgical site infection in patients with abdominal colorectal procedures. Dis Colon Rectum. 2013;56:627-37.

14. Mangram AJ, Horan TC, Pearson ML, Silver LC, Jarvis WR. Guideline for prevention of surgical site infection, 1999. Centers for Disease Control and Prevention (CDC) hospital infection control practices advisory committee. Am J Infect Control. 1999;27: 97-132.

15. Hinchey EJ, Schaal PG, Richards GK. Treatment of perforated diverticular disease of the colon. Adv Surg. 1978;12:85-109.

16. Yamamoto T, Morimoto T, Kita R, Masui H, Kinoshita H, Sakamoto Y, et al. The preventive surgical site infection bundle in patients with colorectal perforation. BMC Surg. 2015;15:128.

17. Degrate L, Garancini M, Misani M, Poli S, Nobili C, Romano F, et al. Right colon, left colon, and rectal surgeries are not similar for surgical site infection development. Analysis of 277 elective and urgent colorectal resections. Int J Colorectal Dis Springer-Verlag. 2011;26:61-9.

18. Uchino M, Ikeuchi H, Tsuchida T, Nakajima K, Tomita N, Takesue Y. Surgical site infection following surgery for inflammatory bowel disease in patients with clean-contaminated wounds. World J Surg. 2009;33:1042-8.
19. Nyström PO, Jonstam A, Höjer H, Ling L. Incisional infection after colorectal surgery in obese patients. Acta Chir Scand. 1987;153: 225-7.

20. Ricciardi R, Roberts PL, Hall JF, Read TE, Francone TD, Pinchot $\mathrm{SN}$, et al. What is the effect of stoma construction on surgical site infection after colorectal surgery? J Gastrointest Surg. 2014;18: 789-95.

21. Fujii T, Tabe Y, Yajima R. Effects of subcutaneous drain for the prevention of incisional SSI in high-risk patients undergoing colorectal surgery. Int J Color Dis. 2011;26:1151-5.

22. Baier PK, Glück NC, Baumgartner U, Adam U, Fischer A, Hopt UT, et al. Subcutaneous Redon drains do not reduce the incidence of surgical site infections after laparotomy. A randomized controlled trial on 200 patients. Int J Color Dis. 2010;25:639-43.

23. Galal I, El-Hindawy K. Impact of using triclosan-antibacterial sutures on incidence of surgical site infection. Am J Surg. 2011;202: 133-8.

24. Chang WK, Srinivasa S, Morton R, Hill AG. Triclosanimpregnated sutures to decrease surgical site infections. Ann Surg. 2012;255:854-9.

25. Cohn SM, Giannotti G, Ong AW, Varela JE, Shatz DV, Mckenney $\mathrm{MG}$, et al. Prospective randomized trial of two wound management strategies for dirty abdominal wounds. Ann Surg. 2001;233:40913 .

26. Morykwas MJ, Argenta LC, Shelton-Brown EI, McGuirt W. Vacuum-assisted closure: a new method for wound control and treatment: animal studies and basic foundation. Ann Plast Surg. 1997;38:553-62.

27. Argenta LC, Morykwas MJ. Vacuum-assisted closure: a new method for wound control and treatment: clinical experience. Ann Plast Surg. 1997;38:563-76.

28. Yoshioka T, Kondo Y, Fujiwara T. Successful wound treatment using negative pressure wound therapy without primary closure in a patient undergoing highly contaminated abdominal surgery. Surg Case Rep. 2018:4:1-5. https://doi.org/10.1186/s40792-018-0493-5.

29. Blackham AU, Farrah JP, McCoy TP, Schmidt BS, Shen P. Prevention of surgical site infections in high-risk patients with laparotomy incisions using negative-pressure therapy. Am J Surg. 2013;205:647-54.

Publisher's Note Springer Nature remains neutral with regard to jurisdictional claims in published maps and institutional affiliations. 